\title{
Incidence of blunt cerebrovascular injuries associated with craniocervical distraction injuries
}

Authors Noojan Kazemi, Carlo Bellabarba, Richard Bransford, Marcelo Vilela

Institution Harborview Medical Center, University of Washington, Seattle, WA, USA

\section{ABSTRACT}

Study design: Retrospective case review.

Introduction: Ischemic insults from blunt cerebrovascular injuries (BCVI) can lead to significant cranial and spinal injury. Specific spine fracture patterns have been identified as more predictive of BCVI, such as vertebral subluxation, fractures through the foramen transversarium, and C1 through C3 fractures. Adequate screening and early treatment has led to a decrease in devastating neurological deficits from associated strokes [1]. However, BCVI in association with injuries of the craniocervical junction have been anecdotally reported but their true incidence is still unknown. We hypothesized that craniocervical dissociation (CCD), due to its distractive nature, is also associated with a high incidence of BCVI.

Objective: To evaluate the incidence of BCVI in a large series of patients with CCD admitted to a singlelevel 1 trauma institution.

Methods: A retrospective review of all consecutive patients diagnosed with unstable craniocervical distraction injuries (defined as abnormal widening of the $\mathrm{C} 0-\mathrm{Cl}$ and/or $\mathrm{Cl}-2$ joints) that were surgically treated from 2003-2009 was performed. All patients with CCD injuries who had a screening catheter angiogram or computed tomographic angiography (CTA) of the neck to exclude BCVI entered the study.

Results: Among 39 consecutive patients identified with CCD (26 men [67\%] and 13 women [33\%] with a mean age of 28.8 years), 28 were screened for BCVI through catheter angiography or CTA. Additional injuries are displayed in Table 1. A total of 14 patients (50\%) who were screened had 25 BCVI, with 12 carotid artery and 13 vertebral artery injuries. These injuries were further subclassified according to the Biffl classification system [2] (Table 2): Biffl 1 (10 patients); Biffl 2 (6 patients); Biffl 3 (5 patients); Biffl 4 (3 patients), and Biffl 5 (1 patient). Among the 18 patients with a purely ligamentous injury of the craniocervical junction, $8(44 \%)$ had a BCVI ( 10 carotid artery and 7 vertebral artery injuries). Among the 10 patients with additional spine fractures that are known risk factors for BCVI, $6(60 \%)$ had a vessel injury ( 6 vertebral artery and 2 carotid artery injuries). Three patients among the 14 with BCVI had a stroke, as opposed to none among the other 14 without BCVI. There was no significant correlation between the presence of BCVI injuries and the presence of abnormal craniocervical distraction as measured by the Harris lines criteria [3].

Conclusions: In patients with craniocervical distraction injuries, the incidence of BCVI is high. Those patients with purely ligamentous injuries had a higher incidence of carotid artery injuries whereas those with associated spine fracture patterns that are known predictive risk factors for BCVI had a higher incidence of vertebral artery injuries. We suggest inclusion of craniocervical distraction injuries as another spine fracture pattern indicative for routine screening of BCVI. 
Table 1 Associated injuries in patients screened for BCVI.*

Table 2 Biffl grading system for blunt traumatic cerebrovascular injuries.

\begin{tabular}{lll}
\hline Associated injury & $\begin{array}{l}\text { BCVI present (14), } \\
\text { No. (\%) }\end{array}$ & $\begin{array}{l}\text { BCVI absent (14), } \\
\text { No. (\%) }\end{array}$ \\
\hline Traumatic brain injury & $9(64)$ & $7(50)$ \\
\hline Craniofacial injury & $8(57)$ & $1(7)$ \\
\hline $\begin{array}{l}\text { Additional C-spine } \\
\text { fractures }\end{array}$ & $6(43)$ & $4(29)$ \\
\hline Skull base fractures & $4(29)$ & $0(0)$ \\
\hline Abdominal injury & $3(21)$ & $2(14)$ \\
\hline
\end{tabular}

\section{Grade Finding}

1 Luminal irregularity or dissection with $<25 \%$ stenosis

2 Dissections with $>25 \%$ luminal narrowing or a raised intimal flap

$3 \quad$ Pseudoaneurysm

$4 \quad$ Complete occlusion

5 Transection of carotid artery, with free extravasation of contrast or significant AV fistula

* BCVI indicates blunt cerebrovascular injuries.

\section{REFERENCES}

1. Biffl WL, Ray CE Jr, Moore EE, et al (2002) Treatment-related outcomes from blunt cerebrovascular injuries: the importance of routine follow-up arteriography. Ann Surg; 235(5):699-707.

2. Biffl WL, Moore EE, Offner PJ, et al (1999) Blunt carotid arterial injuries: implications of a new grading scale. J Trauma; 47(5):845-853.

3. Harris JH, Carson GC, Wagner LK (1994) Radiologic diagnosis of traumatic occipitovertebral dissociation: 1. Normal occipitovertebral relationships on lateral radiographs of supine subjects. AJR Am J Roentgenol; 162:881-886. 